\title{
Research on the Relationship between Level of Rural Human Capital and Urban-Rural Income Gap
}

\author{
Li Chunmei ${ }^{1}$ and Zhao Guiting ${ }^{2}$ \\ ${ }^{I}$ School of Economics and Management, Lanzhou University of Technology, \\ Lanzhou, China \\ ${ }^{2}$ Lanzhou Commercial College, Lanzhou, China \\ licm@lut.cn
}

\begin{abstract}
With the economically backward "Micro-Northwest" region as an example, and the level of rural human capital as a factor affecting urban-rural income gap, this paper conducted an analysis toward the relationship between the level of rural human capital and urban-rural income gap. First, the paper used method of average years of education to measure and calculate the level of human capital in rural areas, and arrived at a conclusion that though the level of rural human capital in Micro-Northwest rose during the period of 1990 and 2010, the rise was slow and the overall level was not high, indicating that it is in phase of the "Nurkse Mode"; Then the paper used group variance method to measure and calculate urban-rural income gap, and through the comparison and analysis, the paper believed that as a whole, the urban-rural income gap in Micro-Northwest was expanding, but its tendency to expand was mild. During its process of rising, the level of rural human capital triggered urban-rural income gap to present as a two-segment periodical inverted " $U$ " curve. Therefore the paper concluded that the improvement of the level of rural human capital in Micro-Northwest did not cause the income gap between urban and rural areas to fall all the while, but rise and fall both. The direction of its influence on the urban-rural income gap was uncertain, which was inconsistent with people's widespread speculations. And finally, from the standpoint of human capital, the paper put forward the countermeasures against reducing urban-rural income gap.
\end{abstract}

Keywords: Micro-Northwest China Economic Area; level of rural human capital; coefficient of urban-rural income gap; method of years of education; interclass variance

\section{Introduction}

The per capital income level of Chinese residents has shown a steady growing tendency since reform and opening up over 30 years ago, while the increases of income levels evaluated with regarding urban and rural residents respectively have not always been so stable. During the period between 1978 and 1988, the rural reform, which had the household contract responsibility system as the core, liberated the agricultural productivity that had been confined for many years, and thus the income level of rural residents increased by a big margin. Since 1989, the increase of rural income has become tardy, especially during the period between 1997 and 2005, the growth remained stagnant. As of 2005, with the promulgation and implementation of series of government policies and measures aimed at supporting agriculture, benefiting the peasants and easing the burden of agriculture, as well as further development of Urbanization, income of rural residents has started to increase. 
Nevertheless, income gap between urban and rural areas and inner-urban and inner-rural income gap are not seen to be narrowed (see Table 1), which becomes one of the main reasons for the problem of lack of effective domestic demand and weak market in recent years.

Table 1. Income Gap Between Urban and Rural

\begin{tabular}{|c|c|c|c|c|c|c|c|c|c|c|c|}
\hline year & 2000 & 2001 & 2002 & 2003 & 2004 & 2005 & 2006 & 2007 & 2008 & 2009 & 2010 \\
\hline urban & 6280 & 6859.6 & 7702.8 & 8472.2 & 9421.6 & 10493 & 11759.5 & 13785.8 & 15780.76 & 17174.65 & 19109.44 \\
\hline rural & 2253.4 & 2366.4 & 2475.6 & 2622.2 & 2936 & 3254.93 & 3587.04 & 4140.36 & 4760.62 & 5153.2 & 5919.01 \\
\hline $\begin{array}{c}\text { Income } \\
\text { gap }\end{array}$ & 4026.6 & 4493.2 & 5227.2 & 5850 & 6485.6 & 7238.07 & 8172.46 & 9645.44 & 11020.14 & 12021.45 & 13190.43 \\
\hline
\end{tabular}

The issue of urban-rural income gap attracts much attention in the field of economic research. There are many factors that affect the income gap between urban and rural areas. After an overview of a large number of relevant literatures, this paper finds that the involving factors include natural factors, social factors, institutional factors and others.

Hou Fengyun and Xu Hui (2004) [1] believed that rural human capital has spillover characteristics, while urban human capital has inner-overflow characteristics. Rural human capital is supporting urban economic development in a long run. Whether in respect of human capital investment or of role playing after the formation of human capital, a deprivation by the city toward the country exists, thus, the urban-rural income gap is enlarged.

Liu Wenxin and Lu Yunhang (2006) [2] found through their research that labor mobility brought about by accumulation of high levels of human capital toward the city can significantly expand urban-rural income gap.

Using the data of Guangdong Province from 1978 to 2006, He Jianfeng and Liu Jianping (2010) [3] made an analysis of the impact of opening to the outside world toward urban-rural income gap. They believed that in the early days of the reform, opening up contributes to the narrowing of income gap between urban and rural areas, but with the decreasing of the proportion of agricultural products in foreign trade gradually, and increasing of processed industrial products, the deepening of the extend of opening to the outside world makes the urban-rural income gap widen intensely. But in long-term, the pulling effect of opening up on urban-rural income gap shows a slightly positive convergence shape.

Using special project funds for science and technology as an indicator that reflects technological advancement, and using per capita disposable income of urban residents and per capita net income of rural residents as an indicator that reflects China's per capita net income for quantitative analysis, Luo Xubin and Hu Delong (2011) [4] found that science and technology advancement difference between urban and rural area has a long-term stable relationship with urban-rural income gap and it has a positive relationship of changing.

Many scholars had conducted various researches on the factors affecting urban-rural income gap, among which there were quantitative analysis as well as qualitative analysis, some talked about the problem from the national level, and others analyzed with a certain province as an example. The scholars either researched the impact on the urban-rural income gap by a number of factors, or studied the impact on the income gap between urban and rural areas by a certain factor. While, taking the economically backward Micro-Northwest China as an example, this paper analyzes the relationship between the level of rural human capital and the urban-rural income gap. It aims to verify whether the improvement of the level of rural 
human capital in the remote and economically backward Micro-Northwest China ${ }^{1}$ has helped narrow the income gap between urban and rural areas and whether the direction of effect toward urban-rural income gap by the level of rural human capital is from beginning to end. The reason why the paper selects the level of human capital in rural areas as the affecting factor to analyze is that there are few researches on the issue from this perspective. Even though there are some that use rural human capital to analyze the urban-rural income gap, they do it in terms of rural human capital investment.

The rest of the paper is organized as follows: Section 2 uses the method of years of education to measure and calculate levels of human capital in rural areas of Micro-Northwest China; Section 3 uses the method of interclass variance to measure and calculate the urbanrural income gap in Micro-Northwest China; Section 4, based on the aforementioned, analyzes the relationship between the level of rural human capital and the urban-rural income gap in Micro-Northwest China; Section 5 analyzes the conclusions and puts forward some relevant suggestions.

\section{Measurement and Calculation of the Level of Rural Human Capital in Micro-Northwest China}

At present, the most commonly used method that measures and calculates the level of human capital is the method of educational deposit. In this paper, using for reference the method by Yang Wenju (2006) [5], it gave different weights ${ }^{2}$ to the different educational levels of the employed in the rural areas of Micro-Northwest China. The weights of the educational levels of the illiterate-and-semiliterate, elementary school, junior high school, senior high school and polytechnic school, college and above are 1, 6, 9, 12 and 16 respectively. Thus, the average years of education of the rural employed in Micro-Northwest China from 1990 to 2010 is:

$$
E_{i t}=\sum_{i=1}^{5} e d u_{i t} P_{i t}
$$

In formula (1), edu $\mathrm{it}_{\mathrm{it}}$ and $\mathrm{P}_{\mathrm{it}}$ indicate respectively the weights of various educational levels and the proportion of employed with different education levels. The paper used the method proposed by Hall and Jones (1999) ${ }^{[6]}$ to construct the time-series data of the level of human capital of the rural employed in Micro-Northwest China, so as to eliminate the differences in marginal returns brought by the incompleteness and asymmetry of the labour substitution between owners of different levels of human capital, which is as shown in formula (2).

$$
H_{i t}=e^{\varphi\left(E_{t i}\right)}
$$

In it, ${ }^{\varphi\left(E_{b}\right)}$ shows a piecewise linear form, and its slope (rate of return to education) is as follows: the rate of the first four years of education is $13.4 \%$, that of the next four years is $10.1 \%$, and that of the education beyond these eight years is $6.8 \%$. The specific calculation formula is as formula (3):

\footnotetext{
${ }^{1}$ The geographically linked Gansu Province, Ningxia Hui Autonomous Region and Qinghai Province in the Northwest region, which lag behind Shanxi Province and Xinjiang Vigor Autonomous Region in economic development, are referred to as "Micro-Northwest China." This wording stems from Professor Nie Hualin, doctoral supervisor of School of Economics, Lanzhou University. See "A Study of Economic Issues in MicroNorthwest China : Regional Economic Integration, Industrial Clusters, Three Rural Issues" [M] by Nie Hualin, Gao Kaishan and Bai Qirui. Beijing: China Social Sciences Press, 2006:45 - 50.

${ }^{2}$ The weights in this article are different from those used in Yang Wenju's article: this article called the illiterate and the semiliterate by a general designation of the illiterate-and-semiliterate, unified the weights of their educational levels as 1, listed polytechnic school and high school together, and unified the weights of their educational levels as 12 .
} 


$$
\varphi\left(E_{i t}\right)=\left\{\begin{array}{l}
0.134 * E_{i t}, E_{i t} \leq 4 \\
0.134 * 4+0.101 *\left(E_{i t}-4\right), 4<E_{i t} \leq 8 \\
0.134 * 4+0.101 * 4+0.068 *\left(E_{i t}-8\right), E_{i t}>8
\end{array}\right\}
$$

The calculated results are shown in Table 2.

\section{Measurement of the urban-rural income gap in Micro-Northwest China}

Table 2. Measurement Table for the Human Capital Level of the Rural Employed in Micro-Northwest China

\begin{tabular}{|c|c|c|c|c|c|c|c|c|c|}
\hline \multirow{2}{*}{ Year } & \multicolumn{4}{|c|}{$\begin{array}{l}\text { Average Years of Education of The } \\
\text { Rural Employed(Years) }\end{array}$} & \multicolumn{4}{|c|}{$\begin{array}{c}\text { Labor Force Population of Rural Areas } \\
\text { (Ten Thousand People) }\end{array}$} & \multirow{2}{*}{$\begin{array}{l}\text { Level of Human } \\
\text { Capital of Rural } \\
\text { Employed in } \\
\text { Micro-Northwest }\end{array}$} \\
\hline & Gansu & Qinghai & Ningxia & $\begin{array}{c}\text { Micro- } \\
\text { Northwe } \\
\text { st }\end{array}$ & Gansu & Qinghai & Ningxia & $\begin{array}{c}\text { Micro- } \\
\text { Northwe } \\
\text { st }\end{array}$ & \\
\hline 1990 & 5.17 & 4.15 & 5.21 & 5.05 & 821.10 & 135.90 & 140.70 & 1097.70 & 1.90 \\
\hline 1991 & 5.57 & 4.60 & 5.38 & 5.42 & 834.50 & 139.80 & 145.50 & 1119.80 & 1.97 \\
\hline 1992 & 5.68 & 4.63 & 5.42 & 5.52 & 848.50 & 143.70 & 149.20 & 1141.40 & 1.99 \\
\hline 1993 & 6.75 & 4.79 & 5.61 & 6.35 & 857.50 & 146.00 & 154.00 & 1157.50 & 2.17 \\
\hline 1994 & 5.89 & 4.85 & 5.67 & 5.73 & 868.00 & 150.00 & 157.00 & 1175.00 & 2.04 \\
\hline 1995 & 6.00 & 4.90 & 6.00 & 5.86 & 876.00 & 152.70 & 162.50 & 1191.20 & 2.06 \\
\hline 1996 & 6.21 & 5.29 & 6.20 & 6.09 & 886.90 & 158.30 & 168.70 & 1213.90 & 2.11 \\
\hline 1997 & 6.32 & 5.32 & 6.24 & 6.18 & 900.40 & 161.40 & 176.70 & 1238.50 & 2.13 \\
\hline 1998 & 6.52 & 5.35 & 6.61 & 6.38 & 906.70 & 162.40 & 181.20 & 1250.30 & 2.17 \\
\hline 1999 & 6.42 & 5.46 & 6.82 & 6.35 & 919.40 & 173.30 & 192.10 & 1284.80 & 2.17 \\
\hline 2000 & 6.90 & 5.53 & 6.88 & 6.71 & 934.50 & 172.00 & 197.90 & 1304.40 & 2.25 \\
\hline 2001 & 6.90 & 5.53 & 6.99 & 6.73 & 942.20 & 174.00 & 200.40 & 1316.60 & 2.25 \\
\hline 2002 & 7.03 & 5.60 & 7.08 & 6.86 & 1008.20 & 177.30 & 203.20 & 1388.70 & 2.28 \\
\hline 2003 & 7.06 & 5.68 & 7.13 & 6.90 & 1050.50 & 180.60 & 208.50 & 1439.60 & 2.29 \\
\hline 2004 & 7.13 & 5.67 & 7.22 & 6.96 & 1057.90 & 184.60 & 209.90 & 1452.40 & 2.30 \\
\hline 2005 & 7.20 & 6.13 & 6.40 & 6.95 & 1084.30 & 186.00 & 212.00 & 1482.30 & 2.30 \\
\hline 2006 & 7.35 & 6.23 & 6.68 & 7.11 & 1090.00 & 187.70 & 213.80 & 1491.50 & 2.34 \\
\hline 2007 & 7.44 & 6.21 & 6.79 & 7.19 & 1095.60 & 189.40 & 214.60 & 1499.60 & 2.36 \\
\hline 2008 & 7.52 & 6.22 & 6.90 & 7.24 & 1389.00 & 277.00 & 304.00 & 1970.00 & 2.37 \\
\hline 2009 & 7.59 & 6.45 & 7.01 & 7.36 & 1106.00 & 196.00 & 218.00 & 1520.00 & 2.40 \\
\hline 2010 & 7.69 & 6.52 & 7.08 & 7.45 & 1113.99 & 198.34 & 218.03 & 1530.36 & 2.42 \\
\hline
\end{tabular}

Currently, among many methods of measuring urban-rural income gap, two of them are more often used by scholars: One is Gini coefficient. Using Gini coefficient to measure income distribution disparity stems from the quantitative change toward the Lorenz curve by Gini. Gini coefficient ranges between 0 and 1. It is an important and internationally accepted indicator reflecting the income gap. The smaller the value, the more the income distribution will tend to average, on the contrary, the more unequal distribution of income will be. During the calculation, the calculated Gini coefficient is often an approximation. The grouping during the calculation of Gini coefficient has an important influence on the extent of its approximation. The fewer the groups are, the greater the error will be; the more the groups are, the smaller the error will be. In the calculation of this paper, if it used the Gini coefficient to measure the income gap between urban and rural areas, taking Micro-Northwest China as a 
whole, and dividing this whole into the two groups of "the city" and "the country", the error would surely be much larger, and the description of data for the facts will distort. In addition, there is a problem of difficulty in calculating the Gini coefficient, so it didn't use the Gini coefficient to measure urban-rural income gap.

The other method is that of the urban-rural income ratio. While using this method, many researchers directly compare the "per capita disposable income of urban residents" with the "per capita net income of rural residents", and they used the size of the ratio to describe the size of the urban-rural income gap. The greater the ratio is, the larger the urban-rural income gap will be, and vice versa. With regard to the urban-rural income ratio, different scholars select different urban-rural income indicators in their actual measurement and calculation: Li Shi and Yue Ximing (2005) [7] used the nominal rate between per capita living expenditure income of urban residents and per capita net income of rural residents to calculate urban-rural income ratio and thus measure the urban-rural income gap; Zeng Guoan and Hu Jingjing (2005) [8] used the nominal ratio between the per capita disposable income of urban residents and the per capita net income of rural residents to measure the urban-rural income gap; Cai Fang and Yang Tao (2000) [9] used the ratio between the per capita disposable income of urban residents and the per capita actual net income of rural residents to measure the urbanrural income gap; Guo Xingfang (2005) [10] used the ratio between the consumption and the savings of urban and rural residents to measure the urban-rural income gap.

No matter which group of urban-rural income indicators the scholars used, the characteristics of the method can be summarized as follows: the advantage is that it is simple to operate and easy to understand, while the disadvantage is that the method has such an assumption that "the numbers of urban and rural residents are equal" that the greater the difference in the number of urban and rural population, the greater the error will be. According to China's current situation of urban-rural population distribution, the rural population is clearly larger than the urban population whether in the whole country, or in a certain province or a large economic zone. Therefore, from a methodological point of view, when the method is used to measure income gap between urban and rural areas, there will be a systematic error.

This paper used the comparable prices with 1990 as the base period to calculate the per capita disposable income of urban residents and the per capita net income of rural residents, and called them respectively the real per capita disposable income of urban residents and the real per capita net income of rural residents. It used the interclass variance method by Wang Yongyu and Liu Huiyong (2011) ${ }^{[11]}$ to measure and calculate the urban-rural income gap in Micro-Northwest China. Residents in Micro-Northwest China are set to be divided into $\mathrm{m}$ groups. Since the analysis was about urban-rural income gap, here it took $m=2$. The urbanrural income gap in Micro-Northwest China is the variance between these two groups, whose value is jointly determined by the two factors of the average income of urban and rural residents (class mean) and the population of urban and rural residents ( class weight ).

The relation between the population variance, the within group variance and the between group variance is: 


$$
\begin{aligned}
& \sigma^{2}=\frac{1}{N} \sum_{i=1}^{m} \sum_{j=1}^{N_{i}}\left(X_{i j}-\bar{X}\right)^{2}=\frac{1}{N} \sum_{i=1}^{m} \sum_{j=1}^{N_{i}}\left[\left(X_{i j}-\bar{X}_{i}\right)+\left(\bar{X}_{i}-\bar{X}\right)\right]^{2} \\
& =\frac{1}{N} \sum_{i=1}^{m} \frac{\sum_{i=1}^{N_{i}}\left(X_{i j}-\bar{X}_{i}\right)^{2}}{N_{i}} N_{i}+\frac{1}{N} \sum_{i=1}^{m}\left(\bar{X}_{i}-\bar{X}\right)^{2} N_{i} \\
& =\frac{1}{N} \sum_{i=1}^{m} \sigma^{2} N_{i}+\frac{1}{N} \sum_{i=1}^{m}\left(\bar{X}_{i}-\bar{X}\right)^{2} N_{i} \\
& =\sigma_{i}^{2}+\sigma_{\bar{X}_{i}}^{2}
\end{aligned}
$$

In formula (4), $\sigma^{2}$ represents the population variance, $\sigma i_{i}^{2}$ means the within group variance of the i-th group, ${ }_{\sigma_{i}^{2}}$ means the weighted average of the within group variance, ${ }^{\sigma_{x_{i}}^{2}}$ means the between group variance, $\mathrm{N}$ is the total population of Micro-Northwest China, $\mathrm{N}_{1}$ is the urban population of Micro-Northwest China, and $\mathrm{N}_{2}$ is the rural population of Micro-Northwest China. The formula is the one in Wang Yongyu and Liu Huiyong (2011) ${ }^{[11]}$, and its principle has been described in detail, so the paper did not repeat it. In order to eliminate the adverse effects of the size of the income gap between urban and rural residents and the overall level of per capita income of residents in various years, in the actual calculation, this paper used the coefficient of variation of the interclass standard deviation of urban and rural residents' income in each of the years to represent the degree of urban-rural income gap, the calculating formula is as follows:

$$
V=\frac{\delta \overline{x_{i}}}{\bar{X}}
$$

In formula (5), $\mathrm{V}$ indicates the coefficient of variation of the interclass standard deviation of urban and rural residents' income, which is referred to herein as "the income gap coefficient of urban-rural residents"; ${ }^{\delta_{\bar{x}}}$ indicates the interclass standard deviation of urban and rural residents; $\bar{x}$ represents the average income of urban and rural residents of MicroNorthwest China. In order to make the data in each of the years comparable, the $\bar{x}$ equals to the weighed average of real per capita disposable income of urban residents and real per capita net income of rural residents. The calculated results are shown in Table 3.

\section{Relationship between Level of Rural Human Capital and Urban-rural Income Gap in Micro-Northwest China}

Based on Table 2 and Table 3 above, the paper drew the trend figure of the level of rural human capital and the trend figure of urban-rural income gap in Micro-Northwest China during 1990-2010, as shown in Figure 1 and Figure 2.

According to Figure 1, it can be directly found that during the 21 years from 1990 to 2010, the overall level of rural human capital in Micro-Northwest China tends to rise, but the increment is very small. According to the research results by Zhou Yunbo and others (2010) ${ }^{[12]}$, the western provinces are mostly in low-level-and-low-growth "Nurkse Mode". Judging from this chart, it can be seen that Micro-Northwest China is in the trap of the low-level-andlow-growth "Nurkse Mode".

According to Figure 2, the urban-rural income gap of Micro-Northwest China during 19902010 takes a clear two-segment and periodical inverted "U" curve, in which the one during 1990-1998 is the first inverted "U" curve, while the one during $1998-2010$ is the second

\footnotetext{
${ }^{3}$ The vicious cycle from low levels of human capital stock to low levels of income to low investment in education and then to slow enhancement of levels of human capital stock is called "Nurkse Mode."
} 
inverted "U" curve. The inverted "U" curve during 1990-1998 is relatively steep, indicating that from 1990 to 1998, the rural-urban income gap in Micro-Northwest China had experienced the two phases of rapid expansion and rapid shrinking. The inverted " $U$ " curve from 1998 to 2010 is relatively flat, indicating that from 1998 to 2010, even though there is a trend of expanding for urban-rural income gap in Micro-Northwest China, this trend is relatively stable, and even since 2007 , a downward trend has begun to appear.

\section{Table 3. Measurement Table for Income, Population, and Coefficient of Urban- Rural Income Gap in Micro-Northwest China during 1990-2010}

Unit: Yuan; Ten thousand people

\begin{tabular}{|c|c|c|c|c|c|c|c|c|c|}
\hline Year & $\begin{array}{c}\text { Real Per } \\
\text { Capita } \\
\text { Disposa } \\
\text { ble } \\
\text { Income } \\
\text { of the } \\
\text { Urban } \\
\text { Resident } \\
\text { s } \\
\text { (Yuan) } \\
\end{array}$ & $\begin{array}{c}\text { Real Per } \\
\text { Capita } \\
\text { Net } \\
\text { Income } \\
\text { of the } \\
\text { Rural } \\
\text { Resident } \\
\text { s } \\
\text { (Yuan) }\end{array}$ & $\begin{array}{l}\text { Urban } \\
\text { Populati } \\
\text { on } \\
\text { (Ten } \\
\text { thousand } \\
\text { people) }\end{array}$ & $\begin{array}{c}\text { Rural } \\
\text { Populatio } \\
n \\
\text { (Ten } \\
\text { thousand } \\
\text { people) }\end{array}$ & $\begin{array}{c}\text { Total } \\
\text { Populatio } \\
\mathrm{n} \\
\text { (Ten } \\
\text { thousand } \\
\text { people) }\end{array}$ & $\begin{array}{c}\text { Real } \\
\text { Per } \\
\text { Capita } \\
\text { Income } \\
\text { (Yuan) }\end{array}$ & $\begin{array}{c}\text { Interclas } \\
\text { s } \\
\text { Variable } \\
\text { of } \\
\text { Urban- } \\
\text { Rural } \\
\text { Resident } \\
\text { s }\end{array}$ & $\begin{array}{c}\text { Interclas } \\
\text { s } \\
\text { Standard } \\
\text { Deviatio } \\
\text { n of } \\
\text { Urban- } \\
\text { Rural } \\
\text { Resident } \\
\text { s }\end{array}$ & $\begin{array}{l}\text { Coefficient } \\
\text { of Urban- } \\
\text { Rural } \\
\text { income Gap }\end{array}$ \\
\hline 1990 & 1259.36 & 468.00 & 769.22 & 2398.65 & 3167.87 & 660.16 & 115141.2 & 339.32 & 0.51 \\
\hline 1991 & 1332.46 & 458.00 & 787.25 & 2432.10 & 3219.35 & 671.84 & 141265.9 & 375.85 & 0.56 \\
\hline 1992 & 1514.02 & 465.68 & 809.10 & 2453.11 & 3262.21 & 728.46 & 204982.1 & 452.75 & 0.62 \\
\hline 1993 & 1544.36 & 451.40 & 836.05 & 2470.88 & 3306.93 & 727.72 & 225653.6 & 475.03 & 0.65 \\
\hline 1994 & 1663.38 & 485.43 & 859.26 & 2505.99 & 3365.25 & 786.20 & 263829.6 & 513.64 & 0.65 \\
\hline 1995 & 1650.70 & 490.44 & 878.65 & 2553.50 & 3432.15 & 787.47 & 256407.0 & 506.37 & 0.64 \\
\hline 1996 & 1630.19 & 564.68 & 898.18 & 2577.98 & 3476.16 & 839.99 & 217549.6 & 466.42 & 0.56 \\
\hline 1997 & 1677.33 & 593.44 & 917.88 & 2601.92 & 3519.80 & 876.09 & 226471.8 & 475.89 & 0.54 \\
\hline 1998 & 1848.17 & 689.49 & 938.00 & 2622.17 & 3560.17 & 994.77 & 260524.9 & 510.42 & 0.51 \\
\hline 1999 & 2092.42 & 693.19 & 956.88 & 2638.50 & 3595.38 & 1065.58 & 382387.0 & 618.37 & 0.58 \\
\hline 2000 & 2315.77 & 718.88 & 973.84 & 2648.19 & 3622.03 & 1148.23 & 501282.6 & 708.01 & 0.62 \\
\hline 2001 & 2611.63 & 726.01 & 1008.86 & 2652.48 & 3661.34 & 1245.58 & 709759.5 & 842.47 & 0.68 \\
\hline 2002 & 2795.68 & 760.58 & 1067.66 & 2625.52 & 3693.18 & 1348.91 & 851175.0 & 922.59 & 0.68 \\
\hline 2003 & 2995.26 & 791.34 & 1130.82 & 2586.32 & 3717.14 & 1461.81 & 1028133. & 1014.00 & 0.69 \\
\hline 2004 & 3245.42 & 841.07 & 1195.35 & 2550.03 & 3745.38 & 1608.43 & 1256157. & 1120.80 & 0.70 \\
\hline 2005 & 3538.27 & 885.22 & 1244.11 & 2489.45 & 3733.56 & 1769.28 & 1563892. & 1250.60 & 0.71 \\
\hline 2006 & 3972.17 & 950.20 & 1284.66 & 2473.29 & 3757.95 & 1983.26 & 2054667. & 1433.40 & 0.72 \\
\hline 2007 & 4208.36 & 991.60 & 1316.30 & 2462.46 & 3778.76 & 2112.13 & 2348890 . & 1532.60 & 0.73 \\
\hline 2008 & 4368.08 & 1053.50 & 1349.25 & 2451.17 & 3800.42 & 2230.26 & 2515704 . & 1586.10 & 0.71 \\
\hline 2009 & 4700.16 & 1130.80 & 1382.20 & 2435.56 & 3817.76 & 2423.07 & 2942613. & 1715.40 & 0.71 \\
\hline 2010 & 4976.82 & 1245.00 & 1381.46 & 2374.54 & 3756.00 & 2617.57 & 3238232. & 1799.50 & 0.69 \\
\hline
\end{tabular}

Source: Derived from relevant data of 1991 to 2011 "Gansu Statistical Yearbook", "Ningxia Statistical Yearbook", "Qinghai Statistical Yearbook" and "China Statistical Yearbook" after reducing inflation.

Using the calculation results of the levels of rural human capital and the coefficient of urban-rural income gap in Micro-Northwest China, the paper made the relationship figure between the two, which is shown as Figure 3. 
From Figure 3, it can be found that there is a relationship of inverted " $U$ " curve with two segments between the level of human capital and the urban-rural income gap in MicroNorthwest China, though the curve is not very regular. The curve from 1990 to 1999 is the first segment of inverted "U" curve, which is relatively steep, indicating that from 1990 to 1999, under the circumstances that the other factors affecting the urban-rural income gap remain unchanged, the rise of the level of rural human capital in Micro-Northwest China has triggered the two phases of rapid expanding and shrinking of urban-rural income gap. The curve from 1999 to 2010 is the second segment of inverted " $U$ " curve, which is relatively flat, indicating that the rise of the level of rural human capital in Micro-Northwest China still causes the expanding of the urban-rural income gap, but the trend of expanding is steady, and when in 2007, it even causes the urban-rural income gap to begin to narrow.

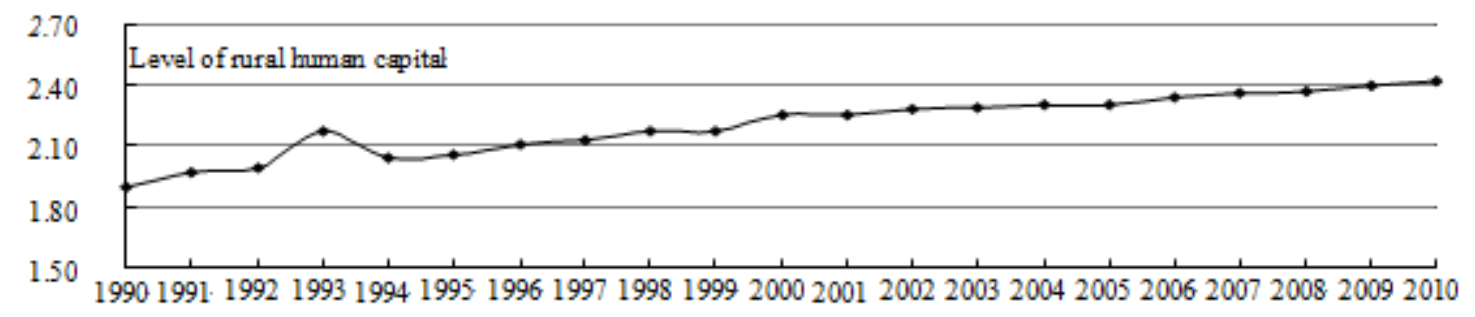

\section{Figure 1. A Trend Figure of the Level of Rural Human Capital in Micro- Northwest China during 1990-2010}

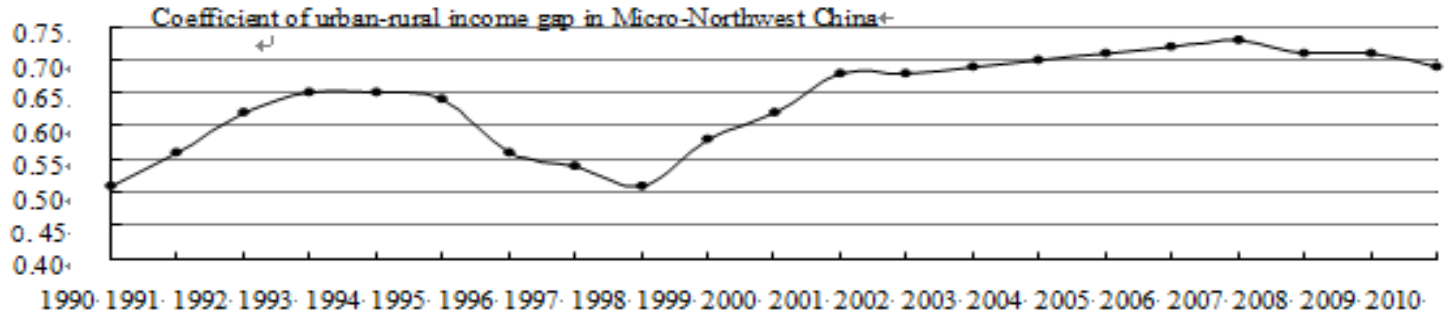

Figure 2. A Trend Figure of Urban-rural Income Gap in Micro-Northwest China during 1990-2010

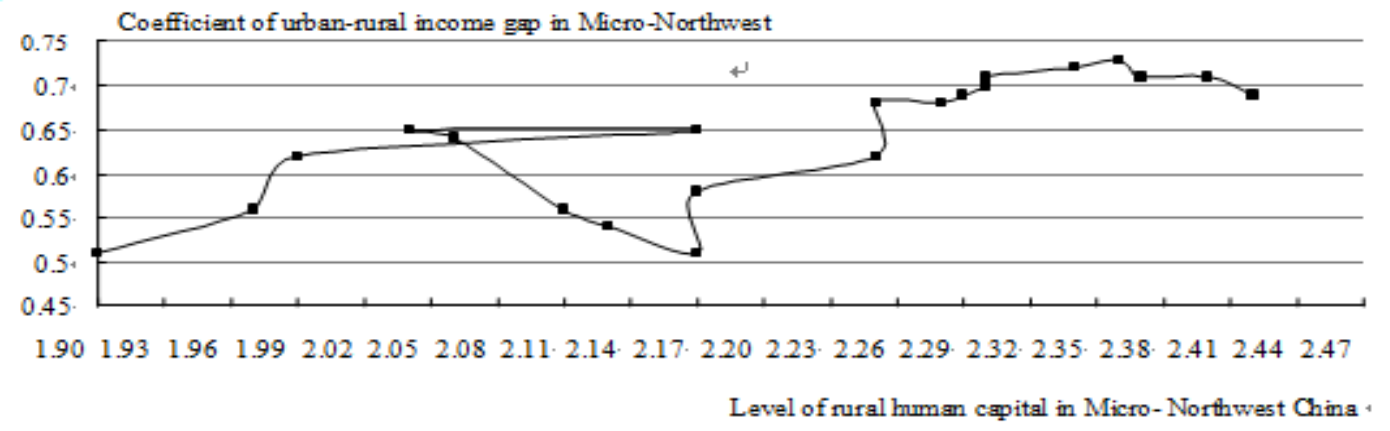

Figure 3. A Figure of relationship between Level of Rural Human Capital and Urban-rural Income Gap 


\section{Conclusions and Suggestions}

\subsection{Conclusions}

1)Though the level of rural human capital in Micro-Northwest China during 1990-2010 is raised, the rise is slow and the overall level is not high, indicating that it is in phase of the "Nurkse Mode".

2)The urban-rural income gap in Micro-Northwest China during 1990-2010 takes a twosegment periodical inverted "U" curve, showing that the overall urban-rural income gap is widening, but its trend to expand becomes flat.

3)With the rising of the rural human capital level in Micro-Northwest China during 19902010, the urban-rural income gap is triggered, which is shown as a two-segment periodical inverted " $U$ " curve. Although the curve is not very neat, and it is also a little roundabout (which may be caused by error of statistical data), the rise of the level of rural human capital does not meet our commonly desired result---making the urban-rural income gap continue to narrow. That is to say, the rise of the level of rural human capital in Micro-Northwest China does not make the urban-rural income gap decrease all the while but rise and fall both, therefore, the direction of influence of the rise of the level of rural human capital in MicroNorthwest China on the urban-rural income gap is uncertain.

\subsection{Suggestions}

In the light of the analysis for the conclusions, from the standpoint of human capital, the paper puts forward the following suggestions to narrow the urban-rural income gap:

As for the analytic conclusion that the overall level of rural human capital in MicroNorthwest China is not high and it is in the "Nurkse Mode", considering from the history and location factors of this region, the paper thinks that it is mainly due to the fact that MicroNorthwest China is located in Northwest China, whose geographic location is remote, the environment of its rural production and living conditions is harsh, it is sparsely populated and has poor infrastructure, its awareness that "knowledge changes destiny" is relatively weak and so on. Now that the natural conditions can not be changed as they already exist there, for example, its geographical remoteness and vast territory with small population can not be changed by manpower, its backward infrastructure, poor conditions of production and living environment and its awareness can be changed. We can change the present situation of backward infrastructure and poor production and living conditions through government financial support as well as the self construction by local rural residents and other ways; we can make the rural residents in the region aware that knowledge can really change their destiny and backward situation through propaganda into villages, through television programs, radio, Internet and other modern information tools or real personal examples and others. At the same time, we have to increase investment in education, popularize compulsory education, deepen higher education, encourage continuing education, and promote construction of vocational schools and on-the-job training, thus greatly increasing the level of rural human capital in Micro-Northwest China to make it get rid of "Nurkse Mode" and gradually enter the "Target Mode".

\footnotetext{
${ }^{4}$ It has a higher level of human capital and also shows a good momentum of sustained, rapid increase. It aims to continue to maintain and cons'olidate existing advantages. Such a mode is a model for other regions to learn from, so it is called the "Target Mode".
} 
As for the current significant feature of "unidirectional spill over" of the rural human capital in Micro-Northwest China, combined with the fact that the rural human capital in Micro-Northwest China is generally low and it is hierarchically single, it needs to improve the production and living conditions in the rural areas, so as to create conditions for the role of "the inner overflow" of rural human capital, realize the "loop effect" of the flow of urban and rural human capital, promote the increase of the income of rural residents in Micro-Northwest China, and then narrow the income gap between urban and rural areas in Micro-Northwest China.

\section{Acknowledgements}

This work is supported by the general project of National Social Science Fund " $A$ Comparative Study on China's Performance of Interregional Industrial Transfer Based on Industrial Structure Optimization" ( No.: 12BJL067).

\section{References}

[1]. H. Fengyun and X. Hui, "Interpretation of Urban-Rural Development Gap through Human Capital", J. Theory Journal, vol. 02, (2004), pp. 42 -45.

[2]. L. Wenxin and L. Yunhang, "Factor Accumulation, Government Policies and China's Urban-Rural Income Gap”, J. Economic Theory and Business Management, vol. 04, (2006), pp. 13-20.

[3]. H. Jianfeng, "Urbanization, Opening Up and Urban-Rural Income Gap: An Empirical Analysis Based on VAR Model”, Technoeconomics \& Management Research, vol. 04, (2010), pp. 16-19.

[4]. L. Xubin and H. Delong, "Research on the Contribution of Technological Progress to the Narrowing UrbanRural Income Gap", Science \& Technology Progress and Policy, vol. 03, (2011), pp. 47-49.

[5]. Y. Wenju, "An Empirical Study on Appropriate Technology Theory and Regional Economic Disparity in China", D. Doctoral Dissertation, Wuhan University, (2006), pp. 74 -78.

[6]. R. E. Hall and C. I. Jones, "Why Do Some Countries Produce So Much More Output per Worker than Others?”, J. Quarterly Journal of Economics, vol. 114, no. 1, (1999), pp. 83-116.

[7]. L. Shi and Y. Ximing, "China Has the Highest Urban-Rural Income Gap in the World", LiLuncankao, vol. 04, (2005), pp. 50-52.

[8]. Z. Guoan and H. Jingjing, "The Evolution, Impact and Regulation Policy Choice of China's Urban-Rural Income Gap since the Late 1970s", Journal of China University of Geosciences, vol. 06, (2005), pp. 1-6.

[9]. C. Fang and Y. Tao, "Political Economy of Urban-Rural Income Gap", Social Sciences in China, vol. 04, (2000), pp.11-22.

[10].G. Xingfang, "Decomposition of Urban-Rural Income Gap", Statistics and Decision, vol. 18, (2005), pp. 6264.

[11].W. Yongyu and L. Huiyong, "Kuznets Effect Analysis for the Urban-Rural Income Gap in Gansu Province", J.Gansu Finance, vol. 04, (2011), pp. 63-65.

[12].Z. Yunbo, W. Peng and Y. Yongze, "Estimation of China's Regional Rural Human Capital and Its Spatial and Temporal Characteristics", China Population Resources and Environments, vol. 09, (2010), pp. 165-170. 